\title{
AS REDES EMPRESARIAIS DE NEGÓCIOS E O SEU PODER COMPETITIVO: RACIONALIDADE LÓGICA OU ESTRATÉGICA? ${ }^{1}$
}

\section{THE BUSINESS-ORIENTED ENTERPRISE NETWORKS AND ITS COMPETITIVE POWER: LOGICAL OR STRATEGICAL RATIONALITY?}

\author{
Ivan de Souza Dutra ${ }^{2}$ \\ Sérgio Baptista Zaccarelli ${ }^{3}$ \\ Sílvio Aparecido dos Santos ${ }^{4}$
}

\begin{abstract}
RESUMO: O objetivo foi analisar como as empresas se agrupam organizando-se sob a forma de uma rede empresarial de negócios, denominada Rede de Negócios. A rede é formada em cooperação para competir com outro grupo de empresas que atua no mesmo setor ou segmento empresarial. A partir de uma discussão do conceito de Rede de Negócios, este estudo faz uma análise teórica e empírica de um caso de rede formada pelo consórcio modular da Volkswagen Caminhões e Ônibus - operações da América do Sul. Entre as principais discussões, constataram-se duas vertentes de racionalização para a teorização sobre redes: a lógica e a estratégica. Evidenciaram-se características e efeitos das Redes de Negócios a partir dessas vertentes. Também, evidenciou-se a posição e poder de negociação entre membros da rede. Observou-se que conforme a forma de pensar, a Rede de Negócios é formada para explorar negócios com base na lógica, ou, é constituída para competir com base pensamento ou raciocínio estratégico. O poder competitivo da rede formada a partir do raciocínio estratégico ficou evidente quando a competição é entre grupos que operam no mesmo ramo e setor. As principais contribuições do estudo são explorar o tema e procurar ampliar a sua discussão.
\end{abstract}

\section{Palavras-chaves: Rede de Negócios; Rede Estratégica; Estratégia}

ABSTRACT: The main objective was analyze how the companies form a group organizing themselves under the form of an enterprise network business-oriented, called Business Network. This kind of network is formed in cooperation to compete with other group of companies that acts in the same sector or enterprise segment. From one discussion of the concept of Business Network, this study makes a theoretical and empirical analysis of a case of a formed network for the modular consortium of the Volkswagen Trucks and Bus - operations of the South America. Between the main discussions, two sources of rationalization had been evidenced for the theorization on networks: the logic and the strategical one. Characteristics and effects of the Business Networks had been proven from these sources. Also, it had been proven the position and power of negotiation between members of the network. It was observed that as the form to think, the business network is formed to explore businesses on the basis of the logic, or, it is constituted to compete based on the thought or strategical reasoning. The competitive power of the network formed from the strategical reasoning was evident when the competition is between groups that operate in the same branch and sector. The main contributions of the study are to explore the subject and to look for extended discussions.

Key-Words: Business Network; Strategic Network; Strategy

\footnotetext{
${ }^{1}$ Artigo Recebido em 16.10.2008 . Revisado por pares em 17.11.2008 . Recomendado em 21.11.2008 por Denise Del Pra Netto Machado (editora). Publicado em 08.12.2008. Organização Responsável pelo periódico: Universidade regional de Blumenau - FURB.

${ }^{2}$ Universidade Estadual do Centro-Oeste (UNICENTRO/PR) - ivan.sdutra@uol.com.br

${ }^{3}$ Universidade de São Paulo (USP) - sbzacca@uol.com.br

${ }^{4}$ Universidade de São Paulo (USP) - sadsanto@usp.br
} 


\section{INTRODUÇÃO}

A necessidade de enfrentar a competição em mercados globais provocou nas últimas duas décadas, mudanças aceleradas nos modelos de gestão e de operação das empresas. Em termos de gestão, as empresas promoveram mudanças em suas fábricas e ou operações. Introduziram as famílias de produtos e serviços globais, integraram suas respectivas cadeias de fornecedores com os recursos da tecnologia da informação, e, reduziram custos dentre outros. O pensamento estratégico dos executivos mudou bastante.

Historicamente, viu-se a competição sob o ângulo de uma empresa concorrendo com as empresas que eram consideradas as suas concorrentes. Agora, em alguns setores, as empresas passaram a se organizar grupalmente formando Redes Empresariais, comumente chamadas de Redes de Negócios, para competir com as redes formadas pelos seus concorrentes.

Existe uma premissa básica na formação das Redes de Negócios: a constatação de que em alguns setores e ou segmentos de negócios, a vantagem competitiva da atuação em grupo organizado sob a forma de rede, pode ser mais facilmente conquistada do que pela atuação isolada e não articulada de uma ou várias empresas. A busca de sinergia entre a força e as competências de cada empresa, permitiu o crescimento da formação das parcerias e alianças estratégicas mesmo entre concorrentes. As novas tecnologias de informação, com o uso intensivo de sistemas integrados, as facilidades de comunicação entre pessoas e empresas, e, a abertura dos mercados no mundo, são fatores que facilitaram e estimularam o surgimento da atuação das empresas em rede.

O próprio incremento da interação das relações entre pessoas e organizações, são fatores intrínsecos à formação de redes empresariais de negócios. É evidente que a atuação das empresas, por meio da formação redes que envolvem negócios que se localizam em diferentes elos da cadeia de valor, altera a competição existente em determinados setores ou segmentos empresariais. Por isso requerem outros padrões de pensamento.

Neste estudo abriu-se uma importante discussão para o tema: a relação entre a forma de racionalizar, entender e definir de Rede de Negócios. Há um grupo de pesquisadores que definem essas redes a partir de determinados fatores ou de configurações, sem necessariamente estabelecer uma relação com a vantagem competitiva. No outro extremo, parte-se da existência da vantagem competitiva dessas redes, que significa a presença da estratégia desde o início da sua constituição. Assim, cada uma destas vertentes comporta uma definição peculiar para a Rede de Negócios, muito diferenciadas entre si.

A questão principal deste estudo é entender a Rede de Negócios e como se organiza na prática da concorrência nacional com outros negócios ou empresas. Procuraram-se aplicar as discussões teóricas, apoiadas pelo exemplo de caso do consórcio em rede da Volkswagen Caminhões e Ônibus - Operações América do Sul em Resende (RJ) com os seus concorrentes no mercado brasileiro.

Para isto dividiu-se este estudo em sete seções, sendo esta "Introdução" a primeira. O problema, assim como os procedimentos metodológicos do estudo, estão na segunda seção. Depois se iniciaram as discussões, presentes nas seções de número 3 e 4 . Na quinta seção, explora-se o estudo de caso do consórcio em rede da Volkswagen Caminhões e Ônibus, para dar sustentação às discussões e analisar o seu poder competitivo. As principais análises sobre a rede em foco estão na sexta seção. Encerra-se com as considerações finais na sétima seção.

\section{O PROBLEMA E OS MÉTODOS DO ESTUDO}

No contexto apresentado da introdução, observou-se o surgimento das Redes de Negócios. A descoberta e discussão desse fenômeno no campo dos estudos organizacionais 
são recentes, com o crescimento da pesquisa científica especialmente a partir da década de 1990, conforme pode ser verificado no trabalho de Oliver e Ebers (1998). Aquele estudo possibilitou constatar a existência de diferentes adoções de abordagens para as redes interorganizacionais, com concepções que tratam de aspectos inerentes à sua própria natureza e extrapolam para um comum com as demais teorizações ou correntes (aspecto ontológico). Também, é fato de que há diferenças no conjunto de conhecimentos que procura explicar o fenômeno dessas redes (aspecto epistemológico), assim como particularmente as Redes de Negócios. Portanto, a pesquisa da temática se encontra no campo das fronteiras dos estudos sobre organizações. Explicar o que são Redes de Negócios, porque existem, como funcionam e quais seus resultados são novos desafios para os estudiosos.

O ponto central a justificar a existência de uma Rede de Negócios, parece estar quando se verifica que um negócio desiste de concorrer de forma isolada para se juntar a outros, com objetivo de ganhar vantagem competitiva. Então, se observa que a estratégia aparece como importante elemento de discussão para dessas redes. Assim, o problema de pesquisa ficou restrito à discussão sobre Rede de Negócios e a Estratégia para contemplar a seguinte questão: O que é uma Rede de Negócios e como se organiza quando se observa a sua prática de concorrer com outros negócios ou empresas do Brasil?

Desta forma a proposta do estudo é fazer uma discussão sobre a definição de Redes de Negócios, o seu poder competitivo e a estratégia, que possa levar a algumas teorizações, observadas por um exemplo prático.

Para os procedimentos metodológicos, Cooper e Schindler (1995), Gil (1999) e Malhotra (2001) caracterizam esta pesquisa de "exploratória", porque a sua concepção objetivou prover a solução do problema que se enfrentou. Gil (1999, p. 43) destaca que as pesquisas deste tipo têm como principal finalidade [...] "desenvolver, esclarecer e modificar conceitos e idéias, tendo em vista, a formulação de problemas mais precisos ou hipóteses para estudos posteriores". A concepção da pesquisa objeto fica então, justificada, por ter um problema bem preciso que oferece condições de desenvolver uma abordagem investigativa, que permita uma discussão seletiva, e, que leve à identificação de aspectos relevantes. De acordo com Malhotra (2001, p. 106-106) neste tipo de pesquisa [...] "As informações necessárias são definidas apenas ao acaso neste estágio e o processo de pesquisa adotado é flexível e não estruturado".

Conforme o contexto das Redes de Negócios já exposto, pouco se sabe a respeito da situação-problema, e, por este motivo, é adequado começar com uma pesquisa exploratória. Além disso, a discussão do tema é reconhecida, mas está em suas fases iniciais no campo do conhecimento da Administração.

Quanto à natureza dos dados são classificados por Cooper e Schindler (1995), Gil (1999) e Malhotra (2001) como "secundários". Dentre as principais fontes desses dados, pesquisaram-se importantes estudos de periódicos ou obras reconhecidos nacional e internacionalmente, dissertação de mestrado e outros, de fontes fidedignas, como dados de associação de classe e de empresa. Os critérios de seleção de tais dados foram a qualidade e confiabilidade do conteúdo.

Para um exemplo prático que oferecesse suporte à discussão investigaram-se intencionalmente estudos de casos. $\mathrm{O}$ critério que se adotou foi a escolha daqueles que tratassem de práticas empresariais e que fosse de encontro ao tema do problema. Dos casos investigados privilegiaram-se aqueles que tiveram importância no cenário empresarial brasileiro e a partir deste universo, optou-se por um deles, por apresentar ótima consistência para estudo, em termos da aplicação do método científico e de conteúdo com seus resultados. 
Então, o processo da amostra do estudo de caso pode ser considerado, "nãoprobabilístico", por sofrer um julgamento (COOPER; SCHINDLER, 1995; MALHOTRA, 2001). Desenvolveu-se uma análise teórica e empírica.

\section{ABORDAGENS E DISCUSSÕES TEÓRICAS EM REDES DE NEGÓCIOS}

O período das décadas de 1970 a 1990 foi marcado pela reestruturação da economia mundial. As inovações tecnológicas se aprofundaram. O ambiente e comércio internacional se intensificaram, e, o fluxo de recursos, seja econômico, social ou de informações adquiriu uma volatilidade em torno do globo. Estas causas foram apontadas por Kumpe e Bolwijn (1994), que analisaram as profundas mudanças das estratégias industriais de multinacionais naquele período.

Kumpe e Bolwijn (1994) procuraram distinguir as corporações em fases evolutivas de mercado e critérios de desempenho. Preocupados em entender a função da área de pesquisa e desenvolvimento, estes autores dividiram as fases em quatro décadas, particularmente entre os anos de 1960 e 1990.

Os anos 1960 uma firma de sucesso possuía uma organização hierárquica, racional e burocrática. $\mathrm{O}$ mercado exigia preço e então, a firma dirigia esforços para incrementar a sua eficiência. A fase foi marcada pela "Firma Eficiente" (KUMPE; BOLWIJN, 1994, p. 38). Na década seguinte, com a quebra de barreiras comerciais ao redor do mundo, decorreu um efeito de crescimento no mercado global. Houve uma intensificação da competição sobre preço, com a produção em um país e a venda de seus produtos por todo mundo. Subseqüente à guerra de preços, as margens de preços se definharam, e, então, as empresas líderes passaram a se diferenciarem pela qualidade. A "Firma Qualidade" foi caracterizada por uma organização hierárquica com gerenciamento competente (KUMPE; BOLWIJN, 1994, p. 39).

$\mathrm{Na}$ passagem para os anos 1980, mais e mais os setores industriais sofreram uma saturação em suas capacidades e com lucros em queda. As firmas procuraram alternativas e as novas tecnologias introduziram novas oportunidades de renovação ou melhoria dos processos e produtos. Ampliaram-se as linhas de produtos com desenhos atualizados, adicionados ao preço e à qualidade em termos mundiais. As corporações tornaram-se flexíveis, com a equalização do fluxo da produção versus a demanda. O sucesso da "Firma Flexível" estava na organização hierárquica, mas externamente "horizontalizada" (KUMPE; BOLWIJN, 1994, p. 41).

Com a equivalência das firmas para cortarem custos, incrementarem os níveis de qualidade e proverem flexibilidade ao mesmo tempo, novamente os competidores mudaram nos anos 1990. Os líderes industriais introduziram mais inovação em seus produtos, com a finalidade de se distinguirem no mercado. Ocorreu uma nova demanda, esta evolução para a "Firma Inovadora" ficou marcada pelo desempenho interno e exclusividade de produtos, por meio da "inovatividade" (KUMPE; BOLWIJN, 1994, p. 42-43).

Já nos anos de 1990, assim como a natureza do trabalho de Kumpe e Bolwijn (1994), podem ser observados o grande volume de estudos organizacionais voltados para a firma em si. Enquanto isso, uma minoria de pesquisadores interessada em estratégia competitiva havia descoberto algo novo: o poder competitivo dos agrupamentos e das redes de negócios.

Thompson (1967) foi precursor no estudo de alianças estratégicas. Os interesses em comum orientavam a estratégia para uma cooperação entre as empresas. Porém, a descoberta do poder competitivo de agrupamentos de negócios foi de Porter (1990, p.131). [...] "as indústrias da nação competitiva não estão economicamente espalhadas de forma uniforme, mas estão ligadas no que eu denomino clusters, que consistem em indústrias que se relacionam por vários tipos de conexões". Com a pesquisa em 10 países do mundo, Porter (1990) explicou que os negócios de algumas cidades se concentravam geograficamente, para produzir um determinado produto. Isto trazia vantagem competitiva no mercado mundial. 
De acordo com Zaccarelli (2004, p. 197) a formação do Cluster é detectada se, o agrupamento de empresas em um distrito industrial de cidade, fizer com que a competição assuma características diferentes. $\mathrm{O}$ autor destaca o caráter da competitividade quando explica que: [...] "É possível traduzir a palavra cluster, quando empregada neste sentido, por agrupamento competitivo, mas, como cluster é um termo consagrado pelo uso, vamos utilizar o anglicismo, sem tradução".

As Redes de Negócios não foram batizadas como os Clusters, porque sua existência já era reconhecida. Entretanto, o seu poder competitivo não estava evidenciado. Elas não são formadas por um agrupamento de negócios em um local, e, dessa forma é mais difícil perceber o efeito conjunto das empresas sobre competitividade. A diferença mais significativa entre o Cluster e a Rede de Negócios é que, aquele tem negócios agrupados geograficamente, enquanto que esta possui negócios dispersos em localidades distintas.

Os últimos 20 anos o campo do conhecimento têm recebido um forte incremento de pesquisas sobre Redes de Negócios, despertado por variados interesses. Pode ser observada a crescente busca para entender o que são, como e porque se formam, constituem, desenvolvem, se mantém e quais os seus resultados.

Inicialmente é preciso situar o contexto das Redes de Negócios. Uma das alternativas é contextualizá-la a partir das diversas correntes teóricas. No escopo das Ciências Sociais, há uma ampla variedade de estudos sobre relações entre atores e organizacionais, também denominadas "redes interorganizacionais". Grande parte desses trabalhos com limites pouco definidos, diferentes focos de pesquisa, distintos exames de desenvolvimento, e, que muitas vezes, se apresentam nas fronteiras dentro desta ciência.

Destarte o considerável aumento no volume de estudos no campo, Oliver e Ebers (1998) discorrem que tal crescimento não assegura uma definida ou especializada acumulação do conhecimento ou mesmo a consolidação conceitual. Ao contrário, isto contribuiu para [...] "uma situação mais propriamente de confusão ou de dificuldade, marcada por uma cacofonia de conceitos, de teorias e de resultados heterogêneos de pesquisa" (OLIVER; EBERS, 1998, p. 549). Observa-se que o campo é vasto, complexo e fragmentado.

Oliver e Ebers (1998) fizeram importantes constatações com os resultados de uma investigação em 158 artigos de importantes periódicos que aceitaram estudos deste campo do conhecimento, a saber, o American Sociological Review, o Administrative Science Quarterly, o Academy of Management Journal e o Organization Studies. Revelaram seis configurações teóricas, derivadas de aplicação da técnica estatística multivariada de análise dos dados em escalamento de três dimensões (MDS).

Desta forma estes autores concluíram que o campo de estudos das relações e redes interorganizacionais, apesar de fragmentado, parece ser segmentado em um número razoavelmente limitado de configurações de perspectivas distintas e teoricamente significativas. Das seis correntes, quatro puderam ser distinguidas pelos autores conforme apresentado no Quadro 1. As outras duas não foram apresentadas no quadro de Oliver e Ebers (1998), por estarem em extremos e não caracterizam um segmento teórico específico. A partir das correntes teóricas sobre redes interorganizacionais definidas por Oliver e Ebers (1998), pode-se considerar que as Redes de Negócios estão predominantemente situadas nas abordagens da Economia Institucional e da Estratégia. 
Quadro 1 - Quatro Configurações Teóricas Distintas e Independentes da Pesquisa

\begin{tabular}{|c|c|c|c|c|}
\hline CONFIGURAÇÃO & $\begin{array}{c}\text { (1) } \\
\text { REDES } \\
\text { SOCIAIS }\end{array}$ & $\begin{array}{l}\text { (2) PODER E } \\
\text { CONTROLE }\end{array}$ & $\begin{array}{c}(3) \\
\text { INSTITUCIONALISTA }\end{array}$ & $\begin{array}{l}\text { (4) ECONOMIA } \\
\text { INSTITUCIONAL } \\
\text { E ESTRATÉGIA }\end{array}$ \\
\hline TEORIAS & Redes. & $\begin{array}{l}\text { Poder Político, } \\
\text { Dependência de } \\
\text { Recursos, Inter- } \\
\text { Trocas }\end{array}$ & Institucional & $\begin{array}{c}\text { Custo de Transação e } \\
\text { Estratégia }\end{array}$ \\
\hline LAÇOS (NÓS) & $\begin{array}{l}\text { Políticos, } \\
\text { Horizontais }\end{array}$ & Políticos & Sociais & $\begin{array}{l}\text { Em Pares, Vertical, } \\
\text { Posse, Contratual }\end{array}$ \\
\hline $\begin{array}{l}\text { NÍVEIS DE } \\
\text { ANÁLISES }\end{array}$ & Individual & Regional/Industrial & $\begin{array}{l}\text { Societal, Grupos de } \\
\text { Indivíduos }\end{array}$ & Organizacional \\
\hline ANTECEDENTES & $\begin{array}{l}\text { Posição na } \\
\text { Rede }\end{array}$ & $\begin{array}{l}\text { Meta Consecutiva, } \\
\text { Dependência, } \\
\text { Conflito }\end{array}$ & $\begin{array}{c}\text { Densidade Organizacional, } \\
\text { Confiança }\end{array}$ & $\begin{array}{l}\text { Coação de Mercado, } \\
\text { Recursos Materiais, } \\
\text { Estabilidade, } \\
\text { Liberalidade de } \\
\text { Recurso, } \\
\text { Especificação da } \\
\text { Propriedade }\end{array}$ \\
\hline RESULTADOS & -- & $\begin{array}{l}\text { Poder/Controle, } \\
\text { Centralização, } \\
\text { Estabilidade, } \\
\text { Participação } \\
\text { Política }\end{array}$ & $\begin{array}{c}\text { Densidade, Conflito, } \\
\text { Legitimidade, Extinção, } \\
\text { Persistência, } \\
\text { Comprometimento, } \\
\text { Confiança, Tamanho }\end{array}$ & $\begin{array}{c}\text { Sucesso, Custo/Preço, } \\
\text { Comando, } \\
\text { Fabricação/Compra, } \\
\text { Oportunismo. }\end{array}$ \\
\hline
\end{tabular}

Fonte: Oliver e Ebers (1998, p.564).

Ainda que selecione a quarta configuração do Quadro 1, verificam-se as diferentes abordagens para as Redes de Negócios. Ao considerar este estudo sobre estratégia, foram separados dois grupos de estudo que podem orientar os seus conceitos: 1) a definir Redes de Negócios sem necessariamente relacioná-las com a vantagem competitiva, e; 2) a definir que as Redes de Negócios existem, quando se detecta vantagem competitiva sobre as empresas de forma isolada.

Orientando-se pelo primeiro grupo, a rede pode ser caracterizada a partir de elementos. A conceituação da empresa em rede dada por Castells (1999, p.191), é

“[...] aquela forma específica de empresa, cujo sistema de meios é constituído pela intersecção de segmentos de sistemas autônomos de objetivos. Assim, os componentes da rede tanto são autônomos, quanto dependentes em relação à rede e podem ser uma parte de outras redes e, portanto, de outros sistemas de meios destinados a outros objetivos."

Human e Provan (1997) discutiram a estrutura e efeitos em redes estratégicas de pequenas empresas (em manufatura). Eles investigaram um grupo formado intencionalmente e orientado para o lucro. Estavam geograficamente próximas e operavam em segmento específico. Estas organizações compartilharam entradas e saídas e empreenderam interrelações para objetivos em negócios. Sem estudar somente os negócios, Marcon e Moinet (2001) discorreram sobre as redes de organizações, as organizações em rede e a estratégia, propondo a necessidade de ampliar a reflexão entre redes de relações e redes de organização. Na concepção destes últimos autores, uma rede organizacional está caracterizada quando há: a) recursos a trocar; b) info-estrutura (conjunto de regras de funcionamento e ética); c) infraestrutura (meios práticos de ação - orçamento, local, comunicação, material, etc.).

As abordagens desses autores e o importante trabalho de Oliver e Ebers (1998) permitiram realizar uma comparação e compilação (dedução) de características para as Redes de Negócios. Então, elaborou-se uma síntese adaptada, que pode ser observado no Quadro 2. 
Quadro 2 - Compilação dos Principais Aspectos sobre O Que é Redes de Negócios e Quais as Suas Características

\section{DESCRIÇÃO}

Formas complexas de organizações, constituídas por:

- Elos que proporcionam inter-relações; trocas entre o ambiente interno da rede e o externo (inputs/outputs), com certa liberalidade;

- Elos (nós) formados por atores ou negócios que detém poder ou prevalência e dão sustentação à rede;

- Objetivos ou interesses em comum;

- Regras em comum (formais ou informais);

- Orientação interna que busca a eficiência/eficácia (ou uma homeostasia ou adaptabilidade);

- Atores ou negócios com certo grau individual de independência, ou não dependência em relação à rede;

- Atores ou negócios pressionados por um ambiente econômico e/ou social em comum;

- Estrutura coletiva de autocontrole e recuperação de resultados;

- Cultura e aprendizagem própria e coevolução

Estruturação e Conjunto - a capacidade coletiva de organização em um sistema de comunicação e atividades para objetivos em comum; capacidade de aglomeração em dimensões geográficas, de atividades, etc.;

Conectividade - a capacidade estrutural de facilitar a comunicação com o menor nível de ruídos entre seus participantes;

Coerência e Reciprocidade - confiança e cooperação sobre interesses compartilhados entre os objetivos da rede e atores;

Poder - um exercício assimétrico econômico ou político de influência ou controle de um negócio sobre o outro;

Necessidade - na dependência ou escassez de recursos ou na velocidade de adaptabilidade das organizações;

Economia - infra-estrutura para a sua sobrevivência ou autosustentabilidade, a gerar desempenho em vantagens econômicas, ou para o processamento e a transmissão da informação que se tornam fontes fundamentais de produtividade e resultados;

Flexibilidade - na propriedade de independência de cada negócio ou na capacidade de adaptação ou reorganização em novas estruturas, ambientes, valores e crenças.

Aprendizagem ou Co-evolução - a capacidade de aprender e crescer conhecimento, evoluir no coletivo ou co-evoluir. Campo de ação dos negócios que pode induzir as várias formações e formas de rede, conforme contingência.

Fonte: Adaptado a partir Castells (1999), Human e Provan (1997), Oliver e Ebers (1998), Marcon e Moinet (2001).

Apesar da objetividade que se procurou apresentar no Quadro 2, observam-se a sobreposição de atributos pelos autores. Então, a orientação conceitual para a definição de uma rede de negócios pode partir da eliminação dos excessos e convergência para oito características mais evidentes que foram propostas aqui: 1) compartilhamento de recursos; 2) práticas informais ou regras; 3) competências sinérgicas ou complementares; 4) reciprocidade; 5) aprendizagem ou co-evolução; 6) poder de troca; 7) posição ou espaço ocupado na rede; 8) alinhamento da proposta de valor. O "atrator" da rede é constituído pelos os interesses de negócios.

Por outro lado, a aplicação do segundo grupo de estudos, que orienta a definição de Redes de Negócios se houver vantagem competitiva, só pode entendida se mudar a forma de pensar. Este contexto será explorado a partir da Estratégia e a Rede de Negócios na próxima seção.

\section{O PENSAMENTO LÓGICO E O ESTRATÉGICO FACE ÀS REDES DE NEGÓCIOS}

Atualmente há uma vasta literatura sobre Administração Estratégica. Na pesquisa de Ramos-Rodriguez e Ruiz-Navarro (2004), que mapearam os estudos mais influentes ou relevantes do Strategic Management Journal, encontraram 870 artigos de 1045 autores. Isto foi tratado somente entre o período de 1980 a 2000, o que se pode ter idéia da grandeza do volume de estudos na área, quando considerado outros períodos e periódicos. 
De forma semelhante, não pela quantidade, mas pela natureza, a conceituação sobre o que é estratégia não é tarefa elementar. Diz e Nalebuff (1994) definem a estratégia como um plano de ação para as decisões sobre ações que ocorrem de forma dinâmica e interativa. Prahalad e Hamel (1990) partiram para uma abordagem de competências dinâmicas. Sob este enfoque, a Administração Estratégica funciona de forma a aprender coletivamente e deve desenvolver e explorar as competências distintivas difíceis de serem imitadas.

A corporação diversificada é entendida por Prahalad e Hamel (1990) como uma árvore de competências. As competências centrais dessa corporação são como as "raízes" da vantagem competitiva. [...] "O sistema de raízes que provê nutrientes, sustento e estabilidade é a competência central". Da mesma forma se desconhece a força de uma árvore ao olhar somente para suas folhas, não pode ser conhecida a força dos concorrentes se olhar somente para os seus produtos (PRAHALAD; HAMEL, 1990, p. 82).

Porém, quando Porter (1990) revelou que em aproximadamente metade dos produtos pesquisados, a vantagem competitiva não era de nações, mas de cidades ou regiões produzidas por agrupamentos de empresas, subentendeu-se que a vantagem não era individualmente das empresas daquelas cidades.

Segue-se o mesmo com as Redes de Negócios, que pode ser entendida como um grupo de empresas que, independente do local onde estejam, obtém vantagem competitiva. Cada negócio, com suas competências distintivas, se junta em uma rede para aumentar a competitividade. Com a união e agindo em conjunto, os negócios se tornam mais fortes. Quando isto ocorre, evidencia-se que também ocorreu a estratégia.

Conforme exposto na seção 3, torna-se difícil a visualização física de uma Rede de Negócios. A dificuldade não está na complexidade dos dados e informações, ou da própria rede, mas na forma de pensar como elas existem. Propõe-se que, para entender como a estratégia ocorre nestas redes é preciso deixar de racionalizar de forma lógica e passar a racionalizar de forma estratégica.

Zaccarelli (2004) discute essas duas alternativas a partir da diferença entre a decisão e a solução. A decisão é usada quando não há possibilidade de ter à disposição todas as informações no momento de iniciar a ação. A solução é usada quando todas as informações necessárias para escolher estão à mão, e assim, justifica-se qual foi a ação para um problema administrativo. Observa que [...] "se você tiver todas as informações relevantes, vai resolver com lógica e será vencedor; se não tiver todas as informações, vai decidir, pois não pode ser lógico e vai correr riscos" (ZACCARELLI, 2004, p. 43).

Em outros termos, um problema que pode ser resolvido pela lógica, levará pessoas diferentes à mesma solução. Quando as incertezas ou diversas probabilidades ocorrem, surge o risco, e, pessoas diferentes, chegam à decisões variadas em face das diferentes variações do risco. [...] "a característica básica dos problemas de estratégia - e que os diferencia dos de lógica - é a existência de oponentes com reações imprevisíveis"(ZACCARELLI, 2004, p.4344).

Pelo mesmo raciocínio, se um negócio concorrente tiver reações previsíveis o problema já estaria situado no campo da lógica. Neste aspecto Zaccarelli (2004, p. 49) argumenta que [...] "O ideal seria chegar a 'prever tudo' para que a decisão se tornasse uma solução lógica, mas isto é praticamente impossível". No entanto os concorrentes, clientes e outros stakeholders reagem muitas vezes de forma diferente e imprevisível. Então se depara com um problema de estratégia. A racionalidade dos estrategistas não está preocupada com o acerto ou com o erro, pois o objetivo é vencer os oponentes.

No caso das Redes de Negócios, uma forma simples e abrangente de entendê-las como funcionam é por meio do mesmo raciocínio proposto por Zaccarelli (2004). Existem empresas ou negócios que se unem em rede para solucionar um problema lógico. Pode estar relacionado 
à cadeia de fornecimento de uma empresa líder, ou sua rede de distribuição quando se procura a redução de custos. A este grupo denomina-se "Rede de Negócios Lógica".

Um exemplo é o caso da Toy'я’Us, das maiores redes de lojas de brinquedos do mundo. Esta empresa criou um modelo de negócio com a eliminação do intermediário de distribuição, o atacadista. Em 1989, com mais de 500 lojas no mundo, a empresa tenta entrar no $2^{\circ}$ maior mercado de brinquedos do mundo: o Japão. Tomou a decisão lógica de associarse a um dos mais experientes empresários, conhecedor do mercado nacional e internacional, o japonês sócio da MacDonalds. Da mesma forma, considerou de forma lógica que o seu sistema canais seria a principal alavanca para conquistar o mercado japonês, como ocorrera em vários outros mercados. Porém, a lei de "Varejo de Larga Escala" do Japão exigia consultar outros varejistas da região. A Тоу'я’Us enfrentou forte oposição dos fabricantes de brinquedos do país (a empresa Bandai se uniu aos demais), que recusaram as vendas diretas, base do sistema de canais da empresa. A empresa enfrentou esse "fracasso" inicial por anos, antes de iniciar um ciclo positivo (KEEGAN; GREEN, 2003).

Num outro extremo pode-se pensar em redes com a racionalidade estratégica. Neste caso as empresas se unem em rede e operam por seus diversos negócios com o principal objetivo de vencer seus concorrentes. Para esta última denominou-se "Rede de Negócios Estratégica". Esta forma de pensar facilita o entendimento da estratégia pela rede. A rede de distribuição de filmes de Hollywood ou a rede da Toyota automóveis são exemplos deste grupo.

Ao observar as Redes de Negócios, a estratégia parece ocorrer por: 1) autoorganização - um processo peculiar de formar um sistema com efeitos surpreendentes e grandiosos, que não poderiam ser considerados como a simples soma do efeito das empresas consideradas isoladamente (formando uma entidade supra-empresas); neste caso não há governança; 2) governança supra-empresas - uma atuação de forma velada e discreta em prol de decisões invisíveis que resultarão em benefícios para o conjunto de todas as empresas (em benefício da entidade supra-empresas); 3) ação de competidor mais poderoso da rede - uma organização ou empresa que detém forte poder de negociação sobre os demais componentes da rede (que alguns autores sarcasticamente chamam de "leão da rede").

Deve-se destacar que a sobrevivência neste ambiente competitivo subiu em amplitude e complexidade. Deixou de ser entre negócios e passou a ser entre redes de negócios. O núcleo da Rede de Negócios é formado estrategicamente para a vantagem competitiva. Combina o conceito dos negócios como um sistema de forma desobstruída das particularizações de abordagens técnica, financeira e humana.

Então, as Redes de Negócios podem ser definidas como 'sistemas', cujas partes mais importantes são as empresas que possuem negócios e se dedicam a um determinado tipo de produto, passando a ter no seu conjunto, um poder de competir muito maior do que as empresas consideradas isoladamente. A essência das redes de negócios foi evidenciada: cada organização separada se especializa no que faz melhor, explorando as vantagens de ser menor, aproveitando as vantagens de estar integrada e maior, criando maior poder de competitividade.

\section{O PODER COMPETITIVO DE UMA REDE DE NEGÓCIOS NO BRASIL: O CASO DA VOLKSWAGEN CAMINHÕES E ÔNIBUS}

Para analisar o poder competitivo de uma Rede de Negócios buscou-se o caso da Volkswagen Caminhões e Ônibus - Operações América do Sul em Resende, RJ, Brasil. Procurou-se discutir a vantagem competitiva alcançada pelo consórcio modular da Volkswagen Veículos Comerciais (VWC), no mercado brasileiro de ônibus e caminhões 
frente aos seus concorrentes. O principal objetivo foi entender como se define a estratégia diante da prática de uma Rede de Negócios em concorrência com outros negócios ou empresas.

Conforme já exposto na seção 3, no período entre 1960 e 1990 as corporações passaram por diversas fases evolutivas, na busca da competitividade e conquista do mercado mundial (KUMPE; BOLWIJN, 1994). A partir de meados da década de 1980, este ambiente mutante e de alta concorrência forçou o setor automobilístico a repensar os seus modelos de gestão. Entre as principais preocupações do setor para a época, estão a redefinição os níveis superiores da cadeia automotiva, que elevou a importância dos fornecedores. As novas formas de estruturar e gerir a cadeia produtiva aumentou a exigência das qualificações das empresas envolvidas e forçou um incremento do segmento de autopeças. Constatou-se o processo de "outsourcing" não somente com a entrega de peças e componentes, mas de subsistemas montados (módulos), com participação direta no processo de montagem do produto final dentro das instalações das montadoras. Isto deu origem aos condomínios industriais (TOLEDO, 2004).

A evolução do condomínio industrial para o modelo de consórcio modular pôde ser observada na VWC. De acordo com Toledo (2003) a fábrica da Volkswagen Caminhões e Ônibus - Operações América do Sul foi inaugurada em 01/11/1996 na cidade de Resende (RJ), resultado de R \$ 300 milhões de investimento, que está sob a responsabilidade da WVC com sede em Hannover, Alemanha. Neste modelo, os principais fornecedores para a montagem de caminhões e chassis de ônibus estão dentro da fábrica, o que permite encomendas sob medida pelos frotistas e transportadores autônomos.

$\mathrm{Na}$ forma de relacionamento entre a WVC e os fornecedores, a linha de montagem é segmentada em módulos sem a manufatura de peças. No primeiro nível da cadeia de fornecimento [...] "todas as atividades produtivas, inclusive a montagem dos veículos são executadas por sete fornecedores (parceiros) que operam de forma conjunta e integrada, sob o mesmo 'teto' e supervisão da montadora, caracterizando, desta forma, a desintegração vertical total da produção por parte da montadora" (TOLEDO, p. 23). Cada módulo é operado por um fornecedor ou consórcio de fornecedores. Todas as operações, investimentos e garantia no módulo são realizados pelos fornecedores. Cabe à montadora a supervisão e teste dos veículos. O sistema foi concebido para a produção em ciclo menor e com custos mais baixos do que o tradicional modelo de montagem do setor. A responsabilidade do setor logístico interno e externo foi atribuída a duas companhias distintas (TOLEDO, 2003).

A princípio, poderia caracterizar este um sistema lógico. Ele tem aproximadamente 1.900 empregados dentro da fábrica, mas apenas 410 são contratados diretamente pela WVC. Visa à integração produtiva para a redução de custos de transportes de produtos, assistência técnica e manutenção industrial. Alcança a produtividade com maneabilidade e confiabilidade. Dividem-se as responsabilidades e flexibiliza-se o negócio.

Ao verificar que o consórcio é regido por um contrato entre os sete fornecedores, justifica-se a natureza da cooperação em um sistema lógico. Conforme Toledo (2003) os membros do sistema foram considerados parceiros que foram escolhidos por critérios de capacitação financeira, tecnológica e de qualidade de serviços com a posição global no mercado. Asseguraram contratualmente a eles a exclusividade e longevidade. Neste grupo estão: a) Iochpe Maxion (módulo chassi); b) Arvin Méritor [Rockwell] (módulo eixos e suspensão); c) Remon [Borlen/Bridgestone/Iochpe] (módulo rodas e pneus); d) Powertrain [Cummins/MWM] (módulo motor); e) AKC e Delga (módulo armação da cabina); f) Carese [Eisenmann] (módulo pintura); g) VDO Mannesmann (módulo tapeçaria).

Porém, se analisar para além das partes, considerará que este sistema é de fato um subsistema de outro maior, a Rede de Negócios WVC. Isto porque unidos de forma interativa 
aos parceiros e fora do território da fábrica, estão muitos negócios que resultam na entrega manufaturada dos componentes ou dos submódulos.

Por exemplo, para o módulo do motor, a MWM fez uma "joint-venture" com a americana Cummins formando a Powertrain. Os motores são produzidos nas plantas industriais das duas primeiras com base em programa da Powertrain, a partir do composto de produção solicitado em função do mercado. A manufatura dos motores na origem também está conectada a um complexo de negócios e logística. A MWM e a Cummins fornecem os motores a diesel utilizados nos caminhões a diversos clientes, aumentando a escala e o poder de negociação, podendo justificar investimentos em pesquisa e desenvolvimento.

No caso da Delga ou da AKC, a manufatura subconjuntos de armação da cabina também não está na fábrica em Resende e forma um subsistema próprio, dentro da teia de negócios. De forma semelhante ocorrem com os demais fornecedores. A esta rede soma-se a rede de distribuidores da WVC. Desta forma participa no mercado do Brasil, mas também na Argentina, Chile, Uruguai, Bolívia, Colômbia, Venezuela Paraguai, Equador, República Dominicana, Costa do Marfim, Nigéria e Arábia Saudita (VWC, 2006).

Assim a Rede de Negócios da WVC (caminhões e ônibus) obteve os seguintes efeitos: a) a especialização do trabalho para a alta competitividade; b) a integração e cooperação entre empresas e negócios; c) a fidelização entre as empresas participantes. Também pode ser observada a ação de empresa com mais poder de negociação (o "leão da rede", conforme proposto na seção 4), que teve a capacidade de unir e coordenar os parceiros do primeiro nível da cadeia produtiva e que influencia toda rede. Algumas evidências podem ser destacadas como resultados desta ação. A estabilização e equilíbrio do fluxo do sistema com a otimização dos canais de marketing. $\mathrm{O}$ aumento no poder de negociação e a introdução de inovações em processos e produtos. Os rendimentos cresceram com o ganho na escala de produção e com um portfólio de produtos mais flexível. O resultado mais importante foi a vantagem competitiva alcançada, com resultados para o maior desempenho no mercado de atuação.

Isto pode ser observado pela comparação no mercado brasileiro de caminhões. Este mercado sempre foi considerado muito promissor, porque o modal rodoviário é o mais representativo no transporte logístico nacional. Há mais de uma década, a participação deste modal na matriz brasileira de transporte é superior a 60\% (ANFAVEA, 2006). No ano em que o consórcio começou a operar, a participação neste mercado estava composta por nove marcas, conforme apresentado na Ilustração 1.

Pode ser observado na Ilustração 1 que a VWC tinha 10,98\% de participação no mercado das principais marcas, se posicionando em $4^{\circ}$ lugar, enquanto que a líder DaimlerCrysler (Mercedes-Benz) detinha 36,58\% de participação. A diferença de $25,6 \%$ foi reduzida a quase zero após 6 anos, quando em 2003 a DaimlerCrysler atingiu 31,61\% de participação e a WVC alcançou 31,23\%, para depois assumir a liderança nos anos seguintes.

Desde o início das operações em 1997, a WVC tem alcançado importantes posições. Por exemplo, os dados da Anfavea (2006) expõem que assumiu a vice-liderança do segmento de médios no ano de 2000 com 33,11\% de participação. Também apresentou o maior crescimento no segmento de pesados, alcançando 4000 unidades/ano em 2002, o que significou um incremento de 10 vezes em 4 anos.

Segundo Toledo $(2003$, p. 233, 238) a explicação de um dos executivos de Resende (RJ) para o crescimento se deveu a cinco fatores: [...] "produto, fábrica, rede de distribuição, foco no negócio e parceria das equipes". Um executivo da VWC mundial expôs: [...] "Resende é interessante porque reage a mercados voláteis. É uma operação lucrativa e extremamente flexível". 
A empresa central desta Rede de Negócios tem maior poder de negociação e o exerce junto aos seus fornecedores. Desta forma obtém condições para tem capacidade de exercer influência sobre os 7 parceiros e muitas vezes sobre os demais fornecedores do subsistema de cada parceiro. Esta influência ocorre em diversas intensidades, mas ao mesmo tempo a empresa procura preservar o parceiro na rede. Por exemplo, quando a VWC adquiriu parte da operação mundial da Scania Caminhões em 1999. Toledo (2003, p 241) expõe que:

[...] "poder-se-ia pensar que a empresa estivesse adquirindo as competências do módulo do motor e transmissão através da compra de um tradicional fabricante sueco de caminhões pesados para finalmente produzir seus próprios motores. Não foi esta a linha de raciocínio da empresa."

Ilustração 1 - Participação no mercado de caminhões das principais marcas entre 1997 e 2006

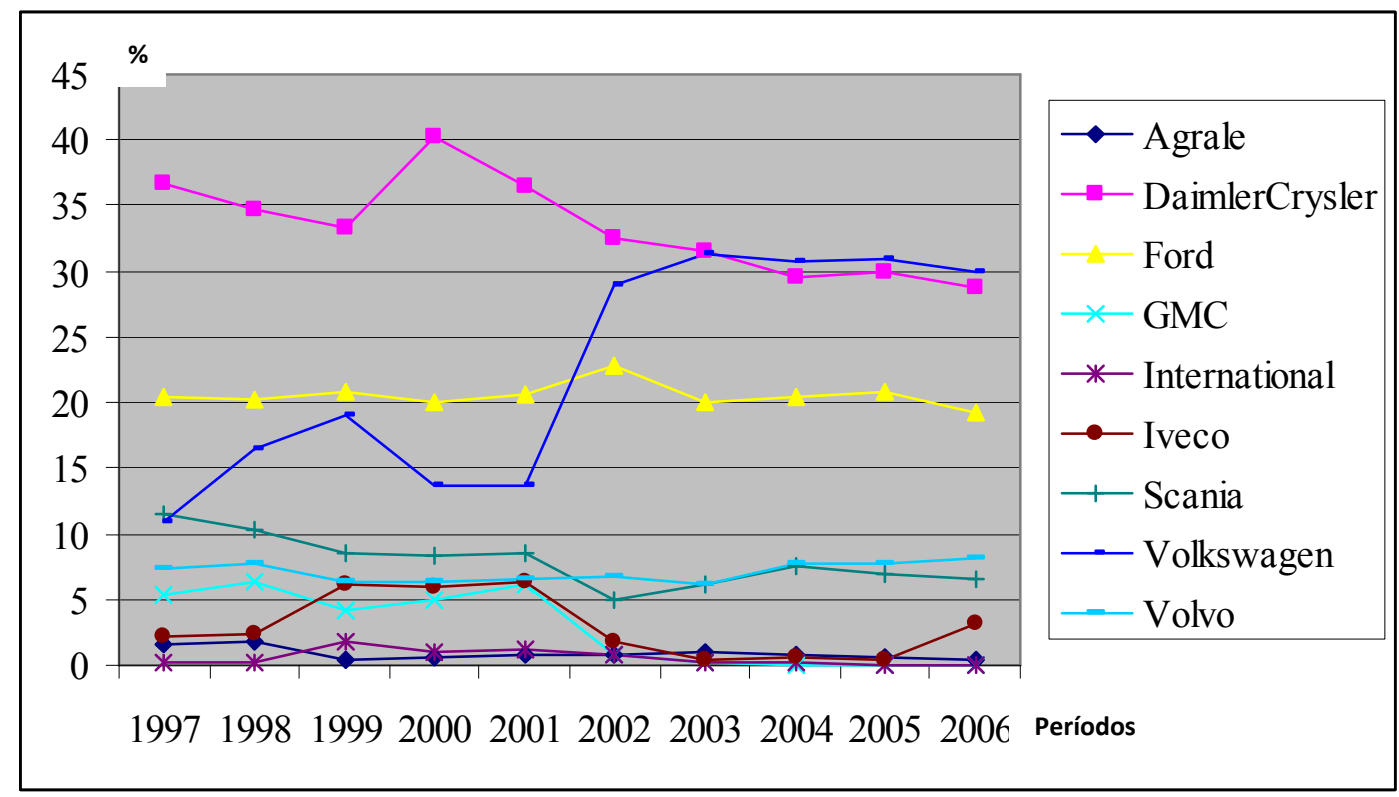

Obs.: As vendas de 2006 se referem aos meses de janeiro a julho. Os dados da International não aparecem no relatório.

Fonte: Anfavea (2006) .

A VWC havia adquirido a empresa sueca para entrar num segmento onde ainda não estava presente, o de caminhões de 45 toneladas. Da mesma forma os parceiros, que são competidores globais, exercem seu poder de negociação sobre os demais, coordenando e controlando atividades em diversos locais do mundo. Procuram estabelecer vínculos mais fortes com os demais fornecedores evidenciando uma fidelização. Eles também participam de outras unidades de negócios. Verifica-se que a necessidade de coordenar o sistema de forma integrada, levou a um estreitamento nas relações na sinergia entre as diversas competências para atender o consumidor final. Conseqüentemente agregou-se valor aos produtos e aumentou-se a lucratividade.

Cada empresa da rede desenvolveu as suas competências e estratégia para atender o resultado coletivo. Toledo (2003, p.247) observa que

[...] "quanto maior a diversidade de produtos e sistemas oferecidos por um fornecedor maior é a sua vantagem competitiva sobre os concorrentes na obtenção de contratos para o fornecimento de complexos sistemas multiprodutos". 
Os riscos são compartilhados entre os membros da rede o que não acontece em um modelo de montadora tradicional. Conforme a VWC obtém desempenho no mercado, os demais parceiros também terão, sendo que o inverso também é verdadeiro.

Entretanto, esta não é uma Rede de Negócios Estratégica consolidada. Há momentos em que prevalecem decisões lógicas. Está em curso um processo de amadurecimento. Um exemplo foi a substituição da Delga por uma associação entre as empresas Aetra e Karmanguia para a produção da cabine de um novo caminhão com produção prevista para 2004, conforme relata Toledo (2003). As duas últimas apresentaram menores custos de produção do que a primeira. Por outro lado verificou-se uma elevação das barreiras de entradas de concorrentes que disputassem o módulo, em razão do investimento realizado e da experiência consolidada no relacionamento com a VWC.

A Rede de Negócios da VWC conseguiu elevar a lealdade dos consumidores em relação à marca. A flexibilidade e sensibilidade ao preço proporcionaram um aumento no grau de atendimento às demandas de mercado e conseqüentemente surgiram maiores margens de lucro. Com as margens mais lucrativas, verificou-se uma capacidade de negociação e flexibilização maior entre os atores da rede. Isto amenizou a força do poder de compra dentro do sistema. Houve um melhor posicionamento quanto aos produtos substitutos. A competição deixou de ser entre empresas e passou para outro nível, o de rede de empresas.

\section{PRINCIPAIS ANÁLISES DO CASO VOLKSWAGEN CAMINHÕES E ÔNIBUS}

O presente estudo aborda o tema Rede de Negócios com a discussão de sua concepção sob duas vertentes. Uma que procura definir as redes a partir de elementos ou características, e, outra que parte da concepção de que essas redes existem para vantagem competitiva e que para compreendê-la é preciso aplicar a racionalidade estratégica.

Quanto à primeira, o caso da Rede de Negócios da VWC no Brasil se apresenta com aderência para as 8 características propostas na seção 3 , que foram elaboradas a partir de Castells (1999), Human e Provan (1997), Oliver e Ebers (1998), Marcon e Moinet (2001). São elas: 1) compartilhamento de recursos - pela troca de recursos materiais e informacionais entre a VWC, os sete parceiros e demais negócios no mundo, com infra-estrutura e velocidade necessárias; 2) práticas informais e regras - que ocorreram a partir de um contrato, mas que se adaptaram e se estenderam em conhecimento tácito e práticas em toda rede; 3) competências sinérgicas ou complementares - a partir das competências dos principais negócios da rede, possibilitaram o provimento de acesso a vários mercados. No caso dos módulos, as empresas individualmente possuíam competências, a exemplo da Cummins e MWM com o motor. Num modelo tradicional de montadora, o domínio da tecnologia do motor é uma competência essencial e entregá-lo a um fornecedor seria considerado um erro estratégico. Porém, a sinergia na rede possibilitou isto com a emersão de outras competências, difíceis de serem imitadas. As principais foram a diversificação com alto grau de atendimento às demanda de mercado; 4) reciprocidade, e; 5) aprendizagem ou co-evolução - com a capacidade que os negócios tiveram para evoluir, melhorando procedimentos, processos, tecnologias e produtos a partir da coletividade; por meio da cooperação para uma estratégia comum. E também pelo aprendizado do novo modelo empresarial e adaptação das pessoas. Este contexto não dá sinais de parar. 6) poder e troca, e; 7) posição ou espaço ocupado na rede - o poder de negociação exercido pela VWC e seus parceiros, entre eles e além deles, assim como as suas influências destacam uma correlação de forças; 8) alinhamento da proposta de valor - por meio de um sistema amplo, mas rápido, flexível e alinhado com as escolhas dos clientes. A proposta de valor da Rede de Negócios da VWC está em oferecer produtos de qualidade mundial a preço 
e características justas. Os interesses da VWC e seus parceiros funcionam como "atratores" da rede.

Para a segunda vertente, propôs-se uma mudança na forma de pensar, quando se comparou a racionalidade lógica e a estratégica (ver seção 4). Sob o enfoque de Zaccarelli (2004) pôde-se observar que no caso da rede em foco, a própria decisão de a VWC criar um consórcio e terceirizar ao extremo toda a montagem do produto, esteve fora da lógica dos modelos industriais mundiais de montadoras de veículos. Isto porque no modelo tradicional, as montadoras entendem que as tecnologias de produção fazem parte de suas competências essenciais, já que depositam grande atenção para as estratégias de produto. Dessa forma há pouca variância em tais competências e um forte direcionamento para um determinado conjunto de componentes que compõe o produto.

Um exemplo evidente disso é a própria Volkswagen no setor de veículos leves (VW), os automóveis. Neste setor é comum as empresas focarem no conjunto do motor e da transmissão. É o que a VW faz com o produto CrossFox ${ }^{\circledR}$, composto de um motor de 1.599 $\mathrm{cm}^{3}$ de cilindrada e potência líquida máxima entre $101 \mathrm{e} 103 \mathrm{cv}$, quando enfatiza a agilidade do veículo. O mesmo ocorre com o produto Gol® que está na $4^{a}$ geração de motores cuja ênfase comercial está na durabilidade do motor e da transmissão (VW, 2006). Toledo (2003) observou a construção da fábrica de motores da VW com investimentos de R \$ 280 milhões. Foi um fato que evidenciou esta estratégia.

A decisão da criação do consórcio modular pareceu inicialmente um contra-senso. A Volkswagen aproveitou o acordo de dissolução da Autolatina para mudar o conceito do seu negócio de caminhões e ônibus, quebrando o compromisso com um modelo organizacional testado. O seu objetivo maior foi o de vencer os seus oponentes.

Entretanto isto pode ser mais facilmente visto pelo por um conjunto de variáveis ou fatores que revelam uma ação conjunta das empresas, quando a Rede de Negócios da VWC tirou a liderança que a DaimlerCrysler (Mercedes-Benz) detinha há décadas no mercado brasileiro de caminhões, em pouco mais de 6 anos. Sob este aspecto destacam-se os seguintes fenômenos: a) fidelização - que cresce no decorrer do tempo com o aumento da competitividade e a evolução entre as transações; b) negócios essenciais - significa que a rede continha todos os negócios significativos para os produtos ofertados; c) alta especialização encontrada na rede o que possibilitou rapidez no atendimento às demandas de mercado; d) substituição seletiva - provocada pela disputa na fabricação de novos produtos quando se encerrou a vigência da forma contratual do consórcio. A mudança da Delga para a AKC no módulo de armação da cabina é um exemplo; e) introdução de novas tecnologias - a introdução de inovação tecnológica está na a política da rede, sob uma forma de coordenação; f) estabilização ou equilíbrio da rede - realizada principalmente pela VWC, mas também pelos parceiros da rede em uma espécie de governança; g) compartilhamento de investimentos, riscos e lucro agregado - ocorre conforme o poder de cada membro da rede, mas pode-se observar que o aumento ou diminuição a lucratividade para a VWC significa o mesmo para os parceiros da rede; h) ação de competidor mais poderoso da rede - sendo o principal ator do consórcio a VWC, que utilizou de seu poder de negociação para estabelecer posições. O principal efeito a constatar foi a governança, movida pela necessidade estratégica para competir com outros concorrentes ou Redes de Negócios.

Então, faz-se necessário destacar que a Rede de Negócios da VWC está formada para competir com vantagem sobre as empresas concorrentes que não estejam organizadas sob a forma de uma rede de negócios. 


\section{CONSIDERAÇÕES FINAIS}

O presente estudo explorou o que é Rede de Negócios, quando observado a prática de sua concorrência com outros negócios ou empresas. Assim, procurou-se discutir a definição de Rede de Negócios a partir de duas vertentes, das quais uma enfoca nos aspectos característicos da rede, e outra a identifica pela prática de sua Estratégia tendo como resultado a vantagem competitiva.

Com base na primeira vertente, as características mais evidentes de uma Rede de Negócios foram: 1) compartilhamento de recursos; 2) práticas informais ou regras; 3) competências sinérgicas ou complementares; 4) reciprocidade; 5) aprendizagem ou coevolução; 6) poder de troca; 7) posição ou espaço ocupado na rede; 8) alinhamento da proposta de valor. Os interesses de negócios funcionam como "atratores" da rede.

A segunda vertente está apoiada na mudança da forma de pensar, da racionalidade lógica para a racionalidade estratégica. Assim a Rede de Negócios pode ser evidenciada a partir da sua estratégia. Desta forma a rede pode ser entendida por variáveis que denotam a ação conjunta das empresas da rede, a saber: a) fidelização; b) presença de negócios essenciais; c) todos com alta especialização; d) substituição seletiva dos relativamente menos competitivos; e) introdução de novas tecnologias; f) estabilização e equilíbrio da rede; g) compartilhamento de investimentos, riscos e lucro agregado; h) ação de competidor mais poderoso da rede. Com base nesta segunda forma de racionalizar, levantaram-se três possibilidades de identificação onde ocorre a estratégia na Rede de Negócios: 1) autoorganização; 2) governança supra-empresas, e; 3) ação do competidor mais poderoso (o leão da rede). Constatou-se no caso da Rede de Negócios da VWC a presença da terceira possibilidade, por meio do poder de negociação.

Do ponto de vista do pensamento empresarial, as Redes de Negócios também podem ser analisadas por meio das duas racionalidades. Assim, o uso do raciocínio lógico também pode resultar na formação de uma Rede de Negócios. Porém, esta teria por objetivo criar facilidades operacionais e ou reduzir custos para as empresas integrantes. Quando o objetivo é vencer através de uma vantagem competitiva, se estabelece o raciocínio estratégico, para buscar o aproveitamento de sinergias, a complementação das forças e geração de valor para os clientes. Isto acaba dando às Redes de Negócio um poder competitivo superior às empresas concorrentes que não estão articuladas em rede.

Nas Redes de Negócios estratégicas o poder de competição decorre da existência de um pensamento estratégico que reúne e define uma estratégia de comportamento coletivo de sinergia, de complementação e agregação de valor. Diante de tais motivos, na própria origem da formação da rede, os executivos de empresas já necessitam aplicar o pensamento estratégico, para garantir que os integrantes da mesma terão em conjunto uma força maior em relação aos seus concorrentes, se comparado com uma atuação de forma isolada e desarticulada.

Então, faz-se necessário destacar que a sobrevivência no ambiente competitivo atual subiu em amplitude e complexidade. Deixou de ser entre negócios e passou a ser entre Redes de Negócios. Os aspectos relacionados aos interesses internos e externos das empresas dessas redes se destacam em decorrência de fatores de competição, da geração de valor, de competências, da colaboração ou cooperação. São apoiados por diversas ações de eficiência e eficácia produtiva, de qualidade, de diferenciação e inovação de produtos ou processos.

A principal limitação do estudo é resultante do seu objetivo, que é ambicioso e não pode ser encontrado por um único caso de Redes de Negócios. Porém, para este ponto de vista 
deve-se considerar o caráter exploratório do estudo. A principal contribuição é ampliar as discussões apresentadas.

Um importante resultado deve ser considerado: que a abordagem da Estratégia em Redes de Negócios é mais simples pela via da racionalidade estratégica. Em termos gerais, o estudo apresentou discussões que procuram contribuir para a compreensão do que é, e, do poder competitivo das Redes de Negócios. Além de novas pesquisas com maior poder de predição para o problema proposto, os autores deste estudo propõem o debate para as seguintes questões: Como as estratégias de cada negócio afetam o desempenho da rede? Existe auto-organização e governança supra-empresas em Redes de Negócios? Quais são as suas condicionantes? Como isto ocorre? Estes questionamentos apontam para uma investigação mais aprofundada e poderá contribuir para melhores práticas empresariais. Tais oportunidades são objetos de futuras pesquisas para os autores deste estudo.

\section{REFERÊNCIAS}

ANFAVEA. Associação Nacional dos Fabricantes de Veículos Automotores (site). São Paulo, 2006. Disponível em: $<$ http://www.anfavea.com.br $>$. Acesso em: 20 Ago. 2006.

CASTEllS, M. A sociedade em Rede. São Paulo: Paz e Terra, 1999.

COOPER, D. R.; SCHINDLER, P. S. Business Reserch Methods. Irwin: McGraw-Hill, 1995.

DIXIT, A. K.; NALEBUFF, B. J. Pensando Estrategicamente: a vantagem competitiva nos negócios, na política e no dia-a-dia. São Paulo: Atlas, 1994.

GIL, A. C. Métodos e técnicas de pesquisa social. São Paulo: Atlas, 1999.

HUMAN, S. E.; PROVAN, K. G. An Emergent Theory of Structure and Outcomes in SmallFirm Strategic Manufacturing Network. Academy of Management Journal. V. 40, n. 2, p. 368-403, 1997.

KEEGAN, Warren J., GREEN, Mark C. Princípios de Marketing Global. Editora Saraiva, 2003.

KUMPE, T.; BOLWIJN, P. T. Toward the Innovative Firm - Challenge for R\&D. Research Technology Management. Jan-Feb, pg. 38-44, 1994.

MALHOTRA, N. K. Pesquisa de Marketing: uma orientação aplicada. Porto Alegre: Bookman, 2001.

MARCON, C.; MOINET, N. Estratégia-Rede. Caxias do Sul: EDUCS, 2001.

OLIVER, A. L.; EBERS, M. Networking Network Studies: An Analysis of Conceptual Configurations in the Study of Inter-organizational Relationships. Organization Studies, 19, 4, p. 549-583, 1998.

PORTER, M. E. The Competitive Advantage of Nations. New York: Free Press, 1990.

PRAHALAD, C. K.; HAMEL, G. The Core Competence of the Corporation. Harvard Business Review. May-Jun, v. 68, n.31, pg. 79-91.

RAMOS-RODRIGUEZ, A. R.; RUIZ-NAVARRO, J. Changes in the Intellectual Structure of Strategic Management Research: a bibliometric study of the Strategic Management Journal, 1980-2000. Strategic Management Journal. V. 25, n. 10, pg. 981-1004, 2004.

THOMPSON, J. D. Organizations in Action. New York: McGraw-Hill, 1967.

TOLEDO, R. M. O Modelo de Consórcio Modular Face aos Desafios Competitivos no Setor Automobilístico: Um Estudo de Caso no Mercado Brasileiro de Veículos Comerciais. Dissertação (Mestrado) - Centro Universitário Municipal de São Caetano do Sul. São Caetano do Sul, 2003. 
VW. Volkswagen do Brasil (site). São Paulo, 2006. Disponível em: $<$ http://www.vw.com.br $>$. Acesso em: 20 ago. 2006.

VWC. Volkswagen Veículos Comerciais. Volkswagen Caminhões e Ônibus (site). São Paulo, 2006. Disponível em: $<$ http://www.vwcaminhoeseonibus.com.br $>$. Acesso em: 20 ago. 2006.

ZACCARELLI, S. B. Estratégia e Sucesso nas Empresas. São Paulo: Saraiva, 2004. 